\title{
Improved Method to Calculate a Water Poverty Index at Local Scale
}

\author{
Ricard Giné Garriga ${ }^{1}$ and Agustí Pérez Foguet ${ }^{2}$
}

\begin{abstract}
The Water Poverty Index (WPI) was created as an interdisciplinary indicator to assess water stress and scarcity, linking physical estimates of water availability with the socioeconomic drivers of poverty. This index has found great relevance in policy making as an effective water management tool, particularly in resources allocation and prioritization processes. Two conceptual weaknesses exist in the current index: (1) inadequate technique to combine available data and (2) poor statistical properties of the resulting composite. The purpose of this paper is to propose a suitable methodology to assess water poverty that overcomes these weaknesses. To this end, a number of combinations to create the WPI have been considered, based on indicators selection criteria, simple aggregation functions and multivariate analysis. The approach adopted has been designed for universal application at local scale. To exemplify the utilization of each alternative method, they have been piloted and implemented in the Turkana District (Kenya) as a case study. The paper concludes that the weighted multiplicative function is the most appropriate aggregation method for estimation of water poverty. It is least eclipsing and ambiguous free function, and it does not allow compensability among different variables of the index.
\end{abstract}

DOI: 10.1061/(ASCE)EE.1943-7870.0000255

CE Database subject headings: Aggregates; Water management; Water shortage; Water policy; Africa; Case studies.

Author keywords: Aggregates; Water management; Water shortage; Water allocation policy; Africa.

\section{Introduction}

The provision of a reliable, sustained, and safe water supply for people worldwide has become a top priority on the international agenda. Water managers are so often faced with an increasing and competing demand, but with limited resources. The issue of prioritization is thus crucial in determining what gets done, and where. Ideally, the decision should be made on who has the most need. If such a decision is made purely on the basis of where water is accessible, this is unlikely to be successful. If on the other hand, there is emphasis on enabling a more equitable allocation of this resource, then decisions need to be made on a much wider basis (Sullivan 2002). In this case, an essential prerequisite to effective decision making would be to access consistent information through accurate monitoring backed up by rigorous interdisciplinary science, which is mainly dependent on a set of reliable and objective indicators. At the same time, reporting on performance is a key component of the management of any insti- tution (Thomson et al. 2005). Again, good information supported by appropriate indicators is required to determine how an institution or sector is faring, whether it is on-track to meet its objectives and what decisions need to be made to maximize performance levels in the future.

Against this background and the necessity to come up with feasible indicators, much effort has gone in recent years into the development of alternatives to assess water problems from many disciplinary perspectives (Falkenmark 1986; Feitelson and Chenoweth 2002; Joint Monitoring Programme 2000; Sullivan 2002). This search for suitable indicators has witnessed the development of a variety of composite indices, which are aimed at condensing information of different nature, thus integrating various social, economic, and environmental aspects of the water sector. Such an index offers policy planners an appropriate tool for performance monitoring, benchmarking comparisons, policy progress evaluation, public information, and decision making.

There are problems with composite indices, however; and they have been criticized on several grounds. Much like many other approaches which attempt to measure complexity, aggregated indices are imperfect tools and caution is required when using them for supporting poverty alleviation. In addition, soundness of composites depends on two aspects (Nardo et al. 2005): (1) the quality of available data and (2) the suitability of techniques employed in their construction. Both elements are equally important. If composite indicators are based on inaccurate information, they would easily be misinterpreted, regardless the adequacy of the method applied to their construction. Likewise, an aggregated index which feeds on comprehensive and coherent basic data but employs poor procedures would produce unreliable results. Development of composite indicators must consider all these aspects.

In low-income settings, any solution to improve water poverty 
assessment needs to be cost effective. It is thus noted that the choice of indicators must rely on readily available information, rather than requiring additional data collection efforts. Consequently, the purpose of this paper is to spotlight a method that supports: (1) the definition of indicators by existing data and (2) their aggregation to create a context-specific index of water poverty. In particular, it is an attempt to refine the Water Poverty Index (WPI) developed by Sullivan (2002). To achieve that outcome, the paper will first introduce the theoretical basis of this index. Its main strengths and limitations are highlighted; and in the light of these shortcomings, different methodologies for weighting and aggregating indicators into a composite are discussed. A step-by-step procedure for constructing the index is proposed. An example of the development of the revised WPI is given for the Turkana District, Kenya as a baseline case to illustrate differences across different methods and to show up potential pitfalls. Overall "water poverty" is calculated by applying different alternatives previously outlined. Integral to this process will be sensitivity analysis to test the robustness of the resulting composites. Main results are discussed. The paper concludes that it is possible to construct an effective index of water poverty which minimizes common pitfalls that arise when constructing the index.

\section{Conceptual Basis to Construct the WPI}

The use of a numerical index as a management tool in water resources assessment has a long and checkered history. Composite indices integrate aspects from different disciplines and nature. In terms of method and technique, the most widespread aggregation function is the summation of equally weighted components consisting of indicators selected in an ad hoc manner. However, numerous criticisms have been leveled at this method.

This section introduces the WPI (Sullivan 2002) as an interdisciplinary tool to assess water scarcity. Despite the relevance of this integrated indicator to assist in water policy making, its major limitations are highlighted. The literature on index development suggests different alternatives to overcome previous limitations, and they are briefly discussed.

\section{Structure and Framework of the WPI}

A sound theoretical framework is the starting point in constructing composite indicators. In this respect, the term water poverty has been amply discussed in recent years (Feitelson and Chenoweth 2002; Sullivan 2002; Shah and van Koppen 2006), though its definition is still being disputed. This paper looks into the concept of water poverty proposed by Lawrence et al. (2003), who state that people can be "water poor" because of two reasons: (1) in the sense of not having sufficient water for their basic needs because it is not available or (2) because they are "income poor"; and although water is available, they cannot afford to pay for it.

Based on this definition, and aimed at assessing the degree to which water scarcity impacts on human populations, the term water poverty was advanced as an indicator by Sullivan (2002) through the WPI. The development of such an index should enable decision makers to identify and track the physical, economic, and social drivers which link water and poverty (Sullivan 2002). Its theoretical framework integrates a number of aspects which reflect major preoccupations in developing countries related to the provision of safe water and improved sanitation: physical availability of water resources $(R)$, extent of access to water and sani- tation $(A)$, people's ability and capacity for sustaining access $(C)$, use of water for different purposes $(U)$, and the environmental factors which impact on the water supply to ecosystems $(E)$. Numerically, the WPI is given by the weighted arithmetic mean function of these five components $(R, A, C, U, E)$. Different weighting systems could thus be employed to indicate the importance of each variable, though equal indicator weights are preferred since there is no evidence that it be otherwise (Sullivan et al. 2003). Likewise, use of an additive structure has been reported more transparent and acceptable to different stakeholders than other aggregation functions (e.g., geometric, multicriteria ...).

\section{Limitations of Existing WPI}

Recognizing the usefulness of the WPI and its spread application (Sullivan et al. 2003; Cullis and O'Regan 2004; Komnenic et al. 2009; Giné and Pérez-Foguet 2009), the writers of the index and literature elsewhere have recognized different concerns that arise when constructing the index. In essence, two conceptual weaknesses have been identified, which this revision here attempts to overcome. One weakness involves how the basic input data are combined, and the other involves the statistical properties of the index.

The ad hoc selection of indicators is subject to criticism. In data-scarce contexts nonetheless, availability and accuracy of data alone often drives the selection process (Booysen 2002). It must be recalled that one objective of the WPI is the use of existing data where possible, rather than identifying data needs regardless availability (Sullivan and Meigh 2003). There is thus built-in flexibility in the choice of indicators, albeit at the cost of comparability. The weighting and aggregation technique is another major shortcoming, since this influences coherence and interpretability of final values (Nardo et al. 2005). The weights assigned to the components of the WPI (which are undefined) are subject to individual judgments (Feitelson and Chenoweth 2002), though an equal average weighting is not adequately justified either. Similarly, Molle and Mollinga (2003) criticized the index for conflating disparate and correlated pieces of information with arbitrary weights. In consequence, Heidecke (2006) pointed to the importance of transparent display of determined weights to avoid misinterpretation. Moreover, it is argued that additive aggregation implies full compensability among the various components of the index: the possibility of offsetting poor performance in some indicators by sufficiently high values of other indicators (Nardo et al. 2005). Such a complete compensability is often not desirable. The WPI has also proved to be inadequate for assessing the complexity of the water issues (Komnenic et al. 2009), and this is acknowledged by the writers (Lawrence et al. 2003) who noted that "the information is in the components rather than in the final single number." Along the same line, the index has been criticized for being unable to reveal anything that a single variable alone cannot reveal. Shah and van Koppen (2006) stated in this respect that the real indicator of water poverty is actually the access component of the WPI, not only suggesting that water resource endowment practically has no relationship with water poverty, but concluding that if a nation is poor, it has no means to exploit its resources. Last but not least, and with regard to the relationship between some of WPI components and other development indicators, Jiménez et al. (2008) showed at international scale that WPI is highly correlated with the Gross Domestic Product (GDP) and Human Development Index (HDI). This reduces the usefulness of the index as a meaningful policy tool.

In sum, significance of WPI tend to be spoilt by a variety of shortcomings including inadequate quality of data, arbitrariness 
of weights, high correlation between WPI and its variables, and loss of information in the aggregation process. There is a need for a reexamination of the composite to ensure its soundness. The following section deals with major constraints related to the methodology employed in index construction. Based on literature review, different alternatives to tackle these limitations are proposed.

\section{Issue of Weights}

In composite indices, the choice of weights is aimed at reflecting the relative importance given to the variables comprising the index. For example in the WPI, greater weight would be placed beside the components which are considered to be more significant in the water poverty context. Different methods to determine weights have been developed, including data-dependent statistical tools as well as judgment-based expert opinions.

A conventional practice is the selection of weights following consultation with experts. However, this is a relatively subjective method of weighting, and it is often singled out for its arbitrariness (Booysen 2002). Alternatively, multivariate techniques (e.g., principal component analysis and factor analysis) present an empirical and more objective option for weight assignment. This technique has the advantage of determining that set of weights which explain the largest variation in the original variables (Slottje 1991). In contrast, weighting only intervenes to correct for the overlapping information of two or more correlated indicators, and it is not a measure of theoretical importance of the associated indicator (Nardo et al. 2005). Therefore, statistical weights do not always reflect the priorities of decision makers (Esty et al. 2005); and since they are data specific, formulations have to be updated when more data become available (Lohani and Todino 1984).

No weighting system is therefore above criticism. Furthermore, it is for this reason that equal weighting is often employed. Main argument for equal indicator weights is based on the premise that no objective mechanism exists to assess the relative importance of the different aspects included in the index structure.

In any case, it has been noted that after experimenting with a variety of weighting systems, resulting indices remain fairly well correlated (Booysen 2002). In terms of index interpretation nonetheless, it is of primary importance to provide an adequate justification for the particular weighting system adopted.

\section{Aggregation Methods}

In much the same way as with the weighting system, there are many aggregating techniques available for constructing an index. By far, the most commonly used method is the weighted arithmetic mean of subindicators. Other, less widespread, aggregation functions include multiplicative (geometric) and nonlinear aggregations such as multicriteria analysis. In this paper, we introduce the additive form employed in the original WPI, in which subindices are added together; and the multiplicative form, in which a product is formed of all of the five components. Numerically, they can be formulated as

$$
\mathrm{WPI}_{a}=\sum_{i=R, A, C, U, E} w_{i} X_{i} ; \quad \mathrm{WPI}_{g}=\prod_{i=R, A, C, U, E} X_{i}^{w_{i}}
$$

where WPI=index value for the arithmetic $\left(\mathrm{WPI}_{a}\right)$ or geometric

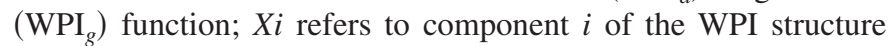
$(R, A, C, U, E)$; and $w=$ weight applied to that component.

Major virtues of an additive approach are simplicity, transparency, and ease of understanding for nonexperts. However, and although widely employed, this aggregation technique imposes certain restrictions on the nature of indicators and the associated weights, which are often not desirable and may be difficult to satisfy (Esty et al. 2005; Nardo et al. 2005).

When using a linear additive aggregation technique, a necessary condition is the assumption of preference independence (Munda and Nardo 2005b). Unfortunately, this condition has very strong consequences, as this means that this aggregation form allows for the estimation of the marginal contributions of the variables separately, which can then be added together to yield a total value (Esty et al. 2005; Nardo et al. 2005). This would imply that among different components of the WPI there are no synergies or conflicts, which appears to be quite an unrealistic assumption. For example, the combined effects on water quality of poor sanitation and environmental degradation around the waterpoint are likely to be more severe than the linear addition of each of these impacts alone.

Furthermore, additive aggregations have important implications on the interpretation of weights, as it has been demonstrated that in a linear aggregation framework weights have the meaning of trade-off (substitution) ratios (Munda and Nardo 2005a). Therefore, there is a theoretical inconsistency in the way weights are actually used and their real theoretical meaning, since they fail to indicate the importance of the variable associated. For the weights to be interpreted as "importance coefficients," noncompensatory aggregation procedures must be used when constructing composite indicators (Podinovskii 1994).

Finally, in linear aggregation rules, compensability among the different individual indicators is implicit (Munda and Nardo 2005b; Nardo et al. 2005). For example in the original WPI, water resources availability would compensate a loss of water quality. Obviously, a complete compensability is not desirable when different goals are equally legitimate, and then a noncompensatory logic might be necessary. In this respect, if multicriteria analysis entails full noncompensability, the use of a geometric aggregation might be an in-between solution (Nardo et al. 2005; Hajkowicz and Collins 2007). In the geometric method, poor performance in some attributes is penalized more heavily.

In addition to the two aggregating techniques employed in this analysis (additive and geometric), further investigation on other methods, e.g., noncompensatory outranking approaches, to construct the WPI would be interesting, though it is beyond the scope of this study.

\section{Developing a Revised WPI}

The idea of obtaining an "ideal index" that captures and perfectly aggregates variables from different dimensions is an unrealistic goal (Diewert 1986, as quoted in Slottje 1991). Instead, Slottje (1991) claimed the need for developing a composite index that balances conceptual clarity (combining as much information as possible) and methodological simplicity (clear understanding of the assumptions that underlie the particular index). Therefore, composite indices should remain simple in terms of their construction and interpretation, allowing for the index to be easily comprehensible and readily calculable (Booysen 2002) and avoiding any complex function which might hinder its transparency. This is certainly imperative regarding the WPI, since it is primarily aimed at informing water managers at local scale in lowincome settings.

This section attempts to operationalize the concept of water poverty. However, to propose one fixed set of indicators for each 
Table 1. Basic Steps in Index Design

1st: selection of indicators

1.a. Compilation and validation of available data

1.b. Definition and first proposal of indicators

1.c. Classification of indicators, based on conceptual framework.

1.d. Preliminary statistical analysis of proposed indicators

1.e. Selection of indicators at subindex level

2nd: construction of the index

2.a. Assignment of weights for subindices

2.b. Aggregation of subindices

3rd: validation of the index

3.a. Sensitivity analysis

and every context appears to be inappropriate, as every location is unique and specific criteria and indicators may not be available for all cases. Therefore, we direct efforts toward the development of a methodological framework to support the selection of appropriate (site-specific) criteria and indicators, and the integration and transformation of this information into a single value.

In essence, composite indexing involves three key steps (Table 1): (1) selection and combination of key indicators into their corresponding subindices, using an equal and dimensionless numeric scale; (2) determination of weight for each subindices and their aggregation to yield an overall index; and (3) validation of the composite using a sensitivity analysis. A step-by-step procedure for developing the WPI is given herein.

The first stage consists of compiling existing sector-related data (1a) and then defining a set of relevant indicators (1b). Information required for good decision making is seldom available, and an information dilemma is often confronted (Feitelson and Chenoweth 2002). The use of available data has the benefit of time and cost savings, though in order to assess whether these advantages are sufficient, it is imperative that further data collection be considered too. The latter might not be a feasible approach in most of poor settlements, and an ad hoc selection of variables driven by data availability appears the most cost-effective solution. In any case, proposed indicators should meet some basic criteria [Organisation for Economic Cooperation and Development (OECD) 1993; Feitelson and Chenoweth 2002; Jiménez et al. 2008]: (1) available (measurable at no/reasonable cost); (2) understandable (exactly defined to be easily accepted by those who are likely to use it); (3) accurate (supported by reliable information); (4) scalable at different administrative levels; (5) relevant (responsive to changes); (6) regularly updatable; and (7) integrative among the environmental, social, and economical aspects.

Next step (1c) is to classify all indicators based on WPI framework; since these five dimensions (subindices) of the index are considered to accurately describe the complexity of water sector in an integrated way. A preliminary assessment of the data set might be helpful to decide whether proposed indicators are appropriate for this purpose. This decision can be based on expert opinion, though different analytical approaches might also be used to explore statistical structure of the data set (Lohani and Todino 1984; Booysen 2002; Nardo et al. 2005).

After having undertaken this general preliminary evaluation, one should repeat this process at subindex level. The underlying nature of the variables needs to be carefully analyzed before the final selection of indicators (1d) (Nardo et al. 2005), which requires a balance between the avoidance of redundancy and comprehensiveness with respect to goals (Keeney and Raiffa 1993, as quoted in Hajkowicz 2006). Lack of correlation is a desired property, which means that each indicator is measuring different statistical dimensions in the data. In contrast, correlated variables cause redundancy and double counting, which might bias the result. Thus, when two or more indicators duplicate measures of same aspect, removal of correlated elements from the model is advisable. The other requirement is comprehensiveness, and the set of selected indicators must be sufficient to thoroughly describe the phenomenon to be measured (Hajkowicz 2006). Multivariate statistical techniques are employed in data reduction to determine the number of latent (correlated) variables underlying the data, and to define new factors which reveal the set of indicators having the highest association with it (Booysen 2002). The idea is to account for the highest possible variation in the indicators set using the smallest possible number of factors. Therefore, the composite no longer depends upon the dimensionality of the data set but it is rather based on the "statistical" dimensions of the data (Nardo et al. 2005). The drawback, though, is that in multivariate techniques correlations do not necessarily represent the real influence of those indicators on the problem at hand (Esty et al. 2005; Nardo et al. 2005). Thus, although methodologically sound, the final choice of which variables are selected should be made on the basis of accurate qualitative and theoretical understanding of the phenomena in question (Booysen 2002; Saisana and Tarantola 2002).

After deciding the number of factors to keep and calculating all five subindices, the assignment of weights is the following step (2a). As previously mentioned, weights should reflect the relative importance of each of the components. To this end, three different approaches might be in place: (1) not to assign explicit weights; (2) weights based on expert opinion; or (3) statistical weights (based on multivariate techniques).

The aggregation process of variables (2b) is certainly a critical step in index construction (Kumar and Alappat 2004; Singh et al. 2008; Swamee and Tyagi 2007). It tends to be of either an additive or a functional nature. The former entails the mere addition of component scores to arrive at index values, whereas the latter is based on a functional relationship between certain variables. A key remark in this respect is that it is important to look at the aggregated figures as well as at the underlying ones.

In the last stage, the index needs to be validated. A sensitivity analysis should be conducted (3a) to test the robustness of the composite. Such analysis might improve the accuracy, credibility, and interpretability of the final results, and thus minimize the risks of producing meaningless composite indicators (Saisana and Tarantola 2002).

\section{Assessing the WPI}

In previous section we outline different alternatives to calculate the index, and their main strengths and limitations are highlighted. This section is aimed at applying all these methods in order: (1) to test their validity; (2) to understand the impact of the selected alternative on final outcome; and (3) to propose an adequate function for estimation of water poverty. To this end, we base on the aforementioned step-by-step procedure. The Turkana District (Kenya) has been selected as initial case study. 


\section{Case Study}

The Turkana district is the largest in Kenya. It is also one of the poorest, with frequent droughts and famines, covering $70,720 \mathrm{~km}^{2}$ of some of the most arid parts of the country. Turkana is located in the Rift Valley Province, and borders on Uganda to the west, Sudan to the northwest, and Ethiopia to the northeast. The district, whose administrative headquarters is at Lodwar, Kenya, is made up of 17 administrative divisions, 58 locations, and 158 sublocations. The population density in this vast district is low, the total population being estimated at 450,860 (1999 National Census).

In recent years, different international agencies and nongovernmental organizations (NGOs) have been working in this region supporting water supply development and management. With the aim of assisting local authorities with strategic planning in the district, United Nations Children's Fund (UNICEF) launched a water and sanitation assessment and mapping project. The initiative (Government of Kenya-UNICEF 2006) was designed to thoroughly record all water resources, visiting up to 644 water sources; assessing 488 rural water supply and sanitation (RWSS) service level points, and compiling related institutional information for 225 schools and 66 health facilities (education and health sector data have not been included in this analysis). Relevant data for each water source were obtained and entered into a geographical information system. Additionally, information related to RWSS service level was captured through a questionnaire administered at community scale. The waterpoint mapping generated sufficient information required to provide an insight into the essence of the variables that affect water poverty. In contrast, data collection methodology did not allow direct link between different survey instruments at a waterpoint, thus present analysis has been undertaken at sublocation level (lowest administrative scale). Moreover, and due to inaccessibility and insecurity in parts of the district, some waterpoints were not audited, which resulted in various sublocations being not covered (41, the percentage of population excluded of analysis roughly being $20 \%$ ). The complete set of data used in this study is available from the writers upon request.

\section{Data Conditioning and Selection of Indicators}

In the first stage, and with regard to data compilation, we exploited the database developed by Government of KenyaUNICEF (2006). A battery of indicators were proposed and sorted into five variables of the index. To each parameter, we assigned a score between 0 and 1 , where a value of 0 was assigned to the poorest level, and 1 to optimum conditions. Continuous variables were normalized to have an identical range $(0,1)$, while rest of parameters were divided in four scale scores $(0,0.33,0.66$, and 1). Levels and scores of all parameters are presented in Table 2 and outlined below. A more detailed description of indicators is given elsewhere (Giné and Pérez-Foguet 2009).

The "resource" component measures availability of water resources, and it was assessed averaging three different variables: (1) water quantity sufficiency, which considers if resource availability is enough to cover human or livestock demand; (2) reliability of supply, meaning period of time system is not operational; and (3) seasonal resource variability. The access variable considers whether or not people have access to safe water and improved sanitation. Besides percentage of population accessing basic services, a set of related indicators were measured: (1) time spent in water collection; (2) cost of water; and (3) op- erational status of the supply. The capacity index tries to capture those socioeconomic variables which can impact on abilities that communities should have to properly manage water sources. Indicators taken into account were thus related to the ability of water entities to oversee operation and management of the supply. The "use" component captures the use people make of the water, although in terms of hygienic practices, ability of beneficiaries to treat water before final consumption was also included as an indicator. Finally, the "environment" component combined a number of indicators which not only cover water quality and "stress," but also variables which are likely to impact on ecological integrity.

Next step was aimed at deciding if the set of proposed indicators was sufficient or appropriate to assess five main components of the index. To this end, a principal components analysis (PCA) was performed to explore whether the variables were statistically well balanced at both index and subindex level. The main goal of this analytical approach is to reduce a complex set of correlated variables into a set of fewer uncorrelated components. On the issue of how factors should be retained in the analysis without losing too much information, this decision was based on the "variance explained criteria," i.e., to keep enough factors to account for $80 \%$ of the variation (Nardo et al. 2005). A Varimax orthogonal rotation was applied to each analysis, in order to maximize variance of factor loadings and thus enhance the interpretability of the results.

When applied at all battery of 25 indicators, this approach showed that 12 factors could explain $81.1 \%$ of the overall variability, and that most of them mixed indicators belonging to different subindices. In this case, PCA did not justify current WPI framework, although it neither offered a better alternative. The adequacy of the original index structure was therefore confirmed in terms of transparency and relevance for the purpose of policy making. The analysis also proved that only two pairs of indicators from different subindices presented correlation coefficients higher than 0.5 (but lower than 0.75 ), which confirms that there were no significant redundancies between them.

At subindex level, a PCA generated two components out of the three initial indicators for the resource component (correlation between indicators R2 and R3), which accounted for 85.39 of the variance in the data set; four components out of six for access (85.3\%; correlation between A1, A3, and A4); three components out of six for capacity $(81.0 \%$; correlation between C3, C4, C5, and C6); four components out of five for use (89.9\%; correlation between U2 and U3); and four components out of five for environment (89.5\%; correlation between E3 and E4). In brief, from an initial set of 25 variables, they were reduced up to 17 noncorrelated indicators.

Based on statistics obtained from previous analysis, all five components of the index were calculated; considering three different alternatives with regard to the contribution (weights) of indicators to each subindex. At this level, since variables can compensate each other's performance, we opted for an additive aggregation.

- Alternative 1-no PCA. Subindices were determined as the straight average of all indicators. This alternative is used in the original WPI (Sullivan 2002), and its main advantages are simplicity and transparency to nontechnical audience.

- Alternative 2-PCA. Subindices were described as the average of raw indicators that loaded most heavily on each principal component; i.e., variables that are most representative of each factor. However, and since some variables are more difficult to measure than others, in cases where two or more 
Table 2. Variables Used, Levels, and Scores (Reprinted with Permission from Giné and Pérez-Foguet (2009))

\begin{tabular}{|c|c|c|c|c|c|}
\hline \multirow{2}{*}{$\begin{array}{l}\text { WPI } \\
\text { component }\end{array}$} & \multirow[b]{2}{*}{ Indicator } & \multicolumn{4}{|c|}{ Levels and scores } \\
\hline & & Fair (1) & Acceptable (0.66) & Poor $(0.33)$ & Risky (0) \\
\hline \multirow[t]{3}{*}{ Resources } & R1: water quantity sufficiency ${ }^{b}$ & Always sufficient & For human and livestock & Only for human & Not sufficient for human \\
\hline & $\begin{array}{l}\text { R2: reliability of supply [time } \\
\text { not operational }(\%)]^{\mathrm{b}}\end{array}$ & $<5 \%$ & $5-10 \%$ & $10-25 \%$ & $>25 \%$ \\
\hline & $\begin{array}{l}\text { R3: seasonal variability of water } \\
\text { resources (months per year with } \\
\text { water) }\end{array}$ & $11-12$ & $9-10$ & $7-8$ & $<7$ \\
\hline \multirow[t]{6}{*}{ Access } & A1: access to safe water ${ }^{a}$ & \multicolumn{4}{|c|}{ Households with access to improved water supply (\%) } \\
\hline & $\begin{array}{l}\text { A2: access to improved } \\
\text { sanitation }^{\text {a }}\end{array}$ & \multicolumn{4}{|c|}{ Households with access to improved sanitation (\%) } \\
\hline & $\begin{array}{l}\text { A3: one way distance to water } \\
\text { source }(\mathrm{km})^{\mathrm{a}}\end{array}$ & $<1$ & $1-2$ & $2-5$ & $>5$ \\
\hline & A4: waiting time $(\min )^{\mathrm{a}}$ & $<30$ & $30-60$ & $60-120$ & $>120$ \\
\hline & $\begin{array}{l}\text { A5: cost of water (KSh per } 201 \\
\text { container) }^{\text {a }}\end{array}$ & $<1$ & $<2$ & $<5$ & $>5$ \\
\hline & $\begin{array}{l}\text { A6: operational status of water } \\
\text { source }\end{array}$ & \multicolumn{4}{|c|}{ Water sources operational (\%) } \\
\hline \multirow[t]{6}{*}{ Capacity } & $\mathrm{C} 1$ : management system ${ }^{\mathrm{b}}$ & \multicolumn{4}{|c|}{ Facilities managed at local level $(\%)$} \\
\hline & $\begin{array}{l}\text { C2: ownership over water } \\
\text { source }^{b}\end{array}$ & \multicolumn{4}{|c|}{ Facilities owned at local level (\%) } \\
\hline & C3: water association registered ${ }^{b}$ & \multicolumn{4}{|c|}{ Facilities managed by associations legally registered $(\%)$} \\
\hline & $\mathrm{C} 4$ : records kept ${ }^{\mathrm{b}}$ & \multicolumn{4}{|c|}{ Water entities which keep records (minutes, correspondences ...) $(\%)$} \\
\hline & C5: financial control ${ }^{\mathrm{b}}$ & \multicolumn{4}{|c|}{ Water entities with financial control system in place $(\%)$} \\
\hline & C6: funds audited ${ }^{\mathrm{b}}$ & \multicolumn{4}{|c|}{ Water entities whose funds are regularly audited $(\%)$} \\
\hline \multirow[t]{5}{*}{ Use } & $\begin{array}{l}\text { U1: domestic water } \\
\text { consumption rate (per capita) }\end{array}$ & $\begin{array}{l}\text { Ample } \\
(>40 \mathrm{lpd})\end{array}$ & $\begin{array}{l}\text { Basic } \\
(20-40 \text { lpd })\end{array}$ & $\begin{array}{l}\text { Limited } \\
(10-20 \text { lpd })\end{array}$ & $\begin{array}{l}\text { Scarce } \\
(<10 \text { lpd })\end{array}$ \\
\hline & $\begin{array}{l}\text { U2: conflict over water sources } \\
\text { (human-human) }\end{array}$ & \multicolumn{4}{|c|}{ Facilities in conflict (\%) } \\
\hline & $\begin{array}{l}\text { U3: conflict over water sources } \\
\text { (human-livestock) }^{\mathrm{b}}\end{array}$ & \multicolumn{4}{|c|}{ Facilities in conflict $(\%)$} \\
\hline & $\begin{array}{l}\text { U4: use of local water treatment } \\
\text { (boil water) }\end{array}$ & \multicolumn{4}{|c|}{ Households who treat water for drinking $(\%)$} \\
\hline & $\begin{array}{l}\text { U5: livestock water use }\left(\mathrm{m}^{3} \mathrm{pd}\right) \\
\mathrm{b}\end{array}$ & $<50$ & $50-100$ & $100-200$ & $>200$ \\
\hline \multirow[t]{5}{*}{ Environment } & $\begin{array}{l}\text { E1: Qualitative assessment of } \\
\text { water quality }^{\mathrm{a}}\end{array}$ & Protected source & $\begin{array}{l}\text { Open source } \\
\text { but treated }\end{array}$ & $\begin{array}{l}\text { Open source, } \\
\text { local treatment }\end{array}$ & $\begin{array}{l}\text { Open source, } \\
\text { no treatment }\end{array}$ \\
\hline & E2: protection of water sources ${ }^{b}$ & \multicolumn{4}{|c|}{ Water facilities protected (fenced) $(\%)$} \\
\hline & $\begin{array}{l}\text { E3: number of pollution sources } \\
\text { (P.S.) around } \mathrm{WP}^{\mathrm{b}}\end{array}$ & None & 1 P.S. & 2 P.S. & $>2$ P.S. \\
\hline & $\begin{array}{l}\text { E4: number of environmental } \\
\text { impacts (E.I.) around } \mathrm{WP}^{\mathrm{b}}\end{array}$ & None & 1 E.I. & 2 E.I. & $>2$ E.I. \\
\hline & $\begin{array}{l}\text { E5: conflict over water sources } \\
\text { (human-wildlife) }^{\mathrm{b}}\end{array}$ & \multicolumn{4}{|c|}{ Facilities in conflict (\%) } \\
\hline
\end{tabular}

\footnotetext{
${ }^{\mathrm{a}}$ Data from RWSS service level.

${ }^{\mathrm{b}}$ Data from water sources audit form.
}

indicators loaded roughly the same, we selected the most easily available one. On the basis of this criterion, in the Resources component the variable "seasonal variability of water resources" was preferred to "supply reliability"; to assess the access subindex, "percent of people who access improved waterpoints" appeared to be more straightforward than "distance to water source"; and in capacity, "legal registration of water entities" was included instead of "funds audit."
This alternative involves fewer indicators (17), and therefore compares favorably with other alternatives in data-scarce contexts.

- Alternative 3-PCA. Factor loading scores were used to determine the weights. Principal component were weighted with the proportion of variance in the original set of variables explained by the first principal component of that particular component. The greater the proportion, the higher the weight. 
Table 3. Weights of Indicators (at Subindex Level)

\begin{tabular}{|c|c|c|c|}
\hline \multirow[b]{2}{*}{ Indicator } & \multicolumn{3}{|c|}{ Weights } \\
\hline & $\begin{array}{l}\text { Alternative } \\
\quad 1\end{array}$ & $\begin{array}{l}\text { Alternative } \\
\quad 2\end{array}$ & $\begin{array}{l}\text { Alternative } \\
\quad 3\end{array}$ \\
\hline R1: water quantity sufficiency & 0.333 & 0.5 & 0.414 \\
\hline R2: reliability of supply & 0.333 & 0 & 0.295 \\
\hline $\begin{array}{l}\text { R3: seasonal variability of water } \\
\text { resources }\end{array}$ & 0.333 & 0.5 & 0.291 \\
\hline A1: access to safe water & 0.167 & 0.25 & 0.113 \\
\hline $\begin{array}{l}\text { A2: access to improved } \\
\text { sanitation }\end{array}$ & 0.167 & 0.25 & 0.220 \\
\hline $\begin{array}{l}\text { A3: one way distance to water } \\
\text { source }\end{array}$ & 0.167 & 0 & 0.140 \\
\hline A4: waiting time & 0.167 & 0 & 0.123 \\
\hline A5: cost of water & 0.167 & 0.25 & 0.206 \\
\hline $\begin{array}{l}\text { A6: operational status of water } \\
\text { source }\end{array}$ & 0.167 & 0.25 & 0.199 \\
\hline $\mathrm{C} 1$ : management system & 0.167 & 0.333 & 0.227 \\
\hline C2: ownership over water source & 0.167 & 0.333 & 0.213 \\
\hline C3: water association registered & 0.167 & 0.333 & 0.139 \\
\hline C4: records kept & 0.167 & 0 & 0.121 \\
\hline C5: financial control & 0.167 & 0 & 0.149 \\
\hline C6: funds audited & 0.167 & 0 & 0.151 \\
\hline $\begin{array}{l}\mathrm{U} 1 \text { : domestic water consumption } \\
\text { rate }\end{array}$ & 0.2 & 0.25 & 0.254 \\
\hline $\begin{array}{l}\text { U2: conflict over water sources } \\
\text { (human-human) }\end{array}$ & 0.2 & 0.25 & 0.155 \\
\hline $\begin{array}{l}\text { U3: conflict over water sources } \\
\text { (human-livestock) }\end{array}$ & 0.2 & 0 & 0,144 \\
\hline $\begin{array}{l}\text { U4: use of local water treatment } \\
\text { (boil water) }\end{array}$ & 0.2 & 0.25 & 0.223 \\
\hline U5: livestock water use & 0.2 & 0.25 & 0.224 \\
\hline E1: water quality & 0.2 & 0.25 & 0.249 \\
\hline E2: protection of water sources & 0.2 & 0.25 & 0.236 \\
\hline E3: number of P.S. around WP & 0.2 & 0 & 0.095 \\
\hline E4: number of E.I. around WP & 0.2 & 0.25 & 0.173 \\
\hline $\begin{array}{l}\text { E5: conflict over water sources } \\
\text { (human-wildlife) }\end{array}$ & 0.2 & 0.25 & 0.248 \\
\hline
\end{tabular}

Note: In bold are indicators included in the sensitivity analysis.

The list of 25 selected indicators along with their weights is presented in Table 3. As might be expected, and though each alternative produce slightly different results, it can be seen that greater differences occur with Alternative 2 (with a reduced number of indicators in all five subindices).

Last step prior to the aggregation of the individual subindices was to examine correlation and redundancy within them. All three alternatives presented poor correlation among their components.

\section{Calculation of WPI}

As discussed above, a major issue in the construction of composite indicators is the choice of the weighting and aggregation model. Since different methods imply different results and given the subjectivity inherent in many of these methods, no alternative employed in composite indexing is above criticism. Keeping this fact in mind, a number of combinations to create the WPI were considered, and each approach was judged based on following criteria (Swamee and Tyagi 2000; Sullivan et al. 2003; Kumar and Alappat 2004; Singh et al. 2008):

- The method should be free or minimize overestimation (ambiguity) and underestimation (eclipsing). Ambiguity problems arise when the aggregate index exceeds the critical level without any of the subindices exceeding the critical levels. In contrast, eclipsing problems exist when the composite does not exceed the critical level, despite one or more of the subindices exceeding the critical levels (Swamee and Tyagi 2000).

- When competing methods produce similar results with respect to ambiguity and eclipsing, the most appropriate methodology is the one that retains the virtues of simplicity and straightforwardness (Sullivan et al. 2003).

- The approach should also be sensitive to the changes in an individual variable throughout its range.

- The method is successful if it is transparent and the index can be readily disaggregated into the separate components with no information lost.

In brief, two different weighting systems were applied, and two aggregation forms were used to combine the five components of the index. It has been mentioned that the aggregation functions considered were the additive and the multiplicative form. The weights were calculated based on expert opinion and the statistical structure of the data set. In both cases, weights were constrained to be nonnegative and sum to one. We first assumed the same approach of the writers of the original WPI as expert opinion (Lawrence et al. 2003; Sullivan et al. 2003); in which key components are not weighted. Second, we performed a multivariate analysis (PCA), and weights were built on the relative importance of the subindices for the principal components. A separate analysis was required depending on the alternative employed in subindex construction, and for the geometric aggregation, weights were computed from PCA of logarithm of the variables. The calculated weights are shown in Table 4 , which confirms that results across different weighting techniques do not differ significantly. It can be seen that the use and environment variables do not completely meet the criterion of independency (lower weights in PCA) for the geometric form. Another overlap applies, to a lesser extent, for the components access and capacity in the additive function. Resources is the subindex which appears to be less correlated.

All different combinations to create the index are presented in

Table 4. Weights and Weighting Systems

\begin{tabular}{|c|c|c|c|c|c|c|c|}
\hline \multirow[b]{2}{*}{ Subindex } & \multirow[b]{2}{*}{ No weights } & \multicolumn{3}{|c|}{ PCA $(\xi)$ additive } & \multicolumn{3}{|c|}{ PCA $(\log \xi)$ geometric } \\
\hline & & Alternative 1 & Alternative 2 & Alternative 3 & Alternative 1 & Alternative 2 & Alternative 3 \\
\hline Resources & 0.2 & 0.253 & 0.251 & 0.255 & 0.223 & 0.221 & 0.225 \\
\hline Access & 0.2 & 0.172 & 0.151 & 0.164 & 0.224 & 0.245 & 0.225 \\
\hline Capacity & 0.2 & 0.187 & 0.182 & 0.186 & 0.218 & 0.216 & 0.215 \\
\hline Use & 0.2 & 0.206 & 0.212 & 0.206 & 0.172 & 0.177 & 0.174 \\
\hline Environment & 0.2 & 0.182 & 0.204 & 0.188 & 0.163 & 0.141 & 0.161 \\
\hline
\end{tabular}


Table 5. Methodologies Applied to Assess WPI

\begin{tabular}{|c|c|c|c|c|c|}
\hline & & \multicolumn{2}{|c|}{ Additive } & \multicolumn{2}{|c|}{ Geometric } \\
\hline \multicolumn{2}{|c|}{ Aggregation form weighting system } & No weights & PCA & No weights & PCA \\
\hline Selection of indicators & $\begin{array}{c}\text { Alternative } 1 \text { (no PCA) } \\
\text { Alternative } 2 \text { (PCA) } \\
\text { Alternative } 3 \text { (PCA) }\end{array}$ & $\begin{array}{l}\mathrm{WPI}_{1, \mathrm{NW}, A} \\
\mathrm{WPI}_{2, \mathrm{NW}, A} \\
\mathrm{WPI}_{3, \mathrm{NW}, A}\end{array}$ & $\begin{array}{l}\mathrm{WPI}_{1, W, A} \\
\mathbf{W P I}_{2, W, A} \\
\mathbf{W P I}_{3, W, A}\end{array}$ & $\begin{array}{l}\mathbf{W P I}_{1, \mathbf{N W}, G} \\
\mathrm{WPI}_{2, \mathrm{NW}, G} \\
\mathrm{WPI}_{3, \mathrm{NW}, G} \\
\end{array}$ & $\begin{array}{l}\mathbf{W P I}_{1, W, G} \\
\mathbf{W P I}_{2, W, G} \\
\mathbf{W P I}_{3, W, G}\end{array}$ \\
\hline
\end{tabular}

Note: In bold are methods included in the analysis.

Table 5. In terms of congruence nonetheless, a logical criterion should be to assume the same method for selection of indicators and assignment of weights; whether the alternative is "no weights" or multivariate techniques. We decided to screen out from the analysis six aggregation functions $\left(\mathrm{WPI}_{1, W, A} ; \mathrm{WPI}_{1, W, G}\right.$; $\mathrm{WPI}_{2, \mathrm{NW}, A} ; \mathrm{WPI}_{2, \mathrm{NW}, G}$; $\mathrm{WPI}_{3, \mathrm{NW}, A}$; and $\mathrm{WPI}_{3, \mathrm{NW}, G}$ ) on the basis of this condition.

The index was thus assessed at sublocation scale applying six remaining functions. Similarly, all sublocations were ranked according to the index value, where a rank of 1 denoted the "lowest" priority (assigned to the sublocation with the highest WPI and thus being the least water poor) and a rank of $n$ denotes highest priority.

To enhance comparability of the functions, different histograms were developed to show the distribution of the resulting indices. From the graphs, it can be seen that regarding the method of variables selection at subindex level, Alternative 2 produces slightly higher results [Fig. 1(a)] since its histogram appears shifted to the left (higher values of WPI). This is basically because of the capacity component, in which three indicators scoring considerably low were removed $(\mathrm{C} 4, \mathrm{C} 5$, and $\mathrm{C} 6)$. As a clear
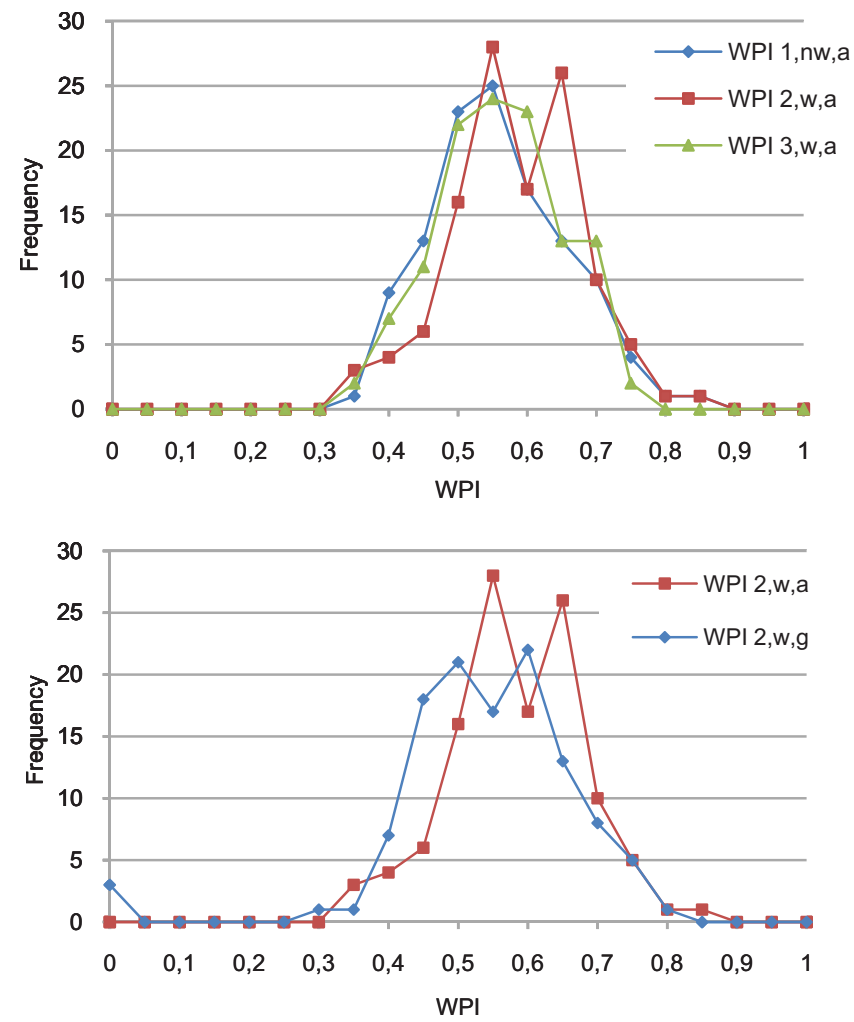

Fig. 1. Histograms of WPI: (a) comparison of the method of variables selection at subindex level; (b) comparison of the aggregation method of variables example to show how the input information used when constructing the index might determine both the final value and the ranking, this particular option (Alternative 2) raises the capacity subindex average from 0.342 (Alternative 1) or 0.411 (Alternative 3) up to 0.561 ; i.e., by $64 \%$ or $36.5 \%$. Likewise, geometric forms score lower than additive functions [Fig. 1(b)], and this has been further discussed in next section.

\section{Sensitivity Analysis}

Index construction involved three stages where subjective judgment was made; i.e., the selection of variables, the attribution of weights, and the choice of aggregation model. Since the quality of WPI significantly depends on the soundness of previous assumptions, sensitivity analyses can help gauge the robustness of the composite and improve its transparency.

We thus analyzed the sensitivity of the results for some sublocations (the highest, medium, and lowest-scoring ones). The results are shown in Table 6. Similarly, an additional sensitivity analysis of the six functions with respect to the changes in two of the most and least significant variables from Table 3 ("water quantity" and "human-human conflict over water sources") was performed independently.

According to Table 6, it is confirmed that water poverty levels appear to increase (lower values of WPI) if a geometric function is applied, though this difference might be extremely inflated if only lowest positions are considered. In particular, the additive form raises the average WPI score from 0.492 to 0.535 for Alternative 1 (i.e., by $8.56 \%$ ); from 0.515 to 0.557 for Alternative 2 (8.16\%); and from 0.496 to 0.537 for Alternative $3(8.28 \%)$. This is also depicted in Fig. 2(a), in which the variation of $\mathrm{WPI}_{2, W}$ values for the geometric aggregation with respect to the changes of its respective linear function is plotted. In this respect, and though both indices remain fairly well correlated, it has to be noted that all values are located below the $x$ (additive) $=y$ (geometric) line. A similar plot could be observed (not shown here) and analogous conclusions could be reached for the two remaining pair of indices $\left(\mathrm{WPI}_{1, \mathrm{NW}}\right.$ and $\left.\mathrm{WPI}_{3, W}\right)$. Another remark regarding the geometric aggregation is that some sublocations scored 0 , as this method does not allow compensation in case null values in any variable. Despite being meaningless in terms of water poverty, this result supports the fact that multiplicative forms more accurately identify the hot spots of the data set.

The rankings are also affected, though no clear rule could be established [see also Fig. 2(b)]. It is gleaned from Table 6 that at the top end nothing changes very much, apart from three sublocations which show a slight tendency to slip to a lower position. At the medium of the list, ranks vary significantly, and greater differences occur depending on the method employed to select the variables, being "Alternative 2" considerably more sensitive. It is also noted that significant gains in rank position (more than 10 points) when a multiplicative aggregation form is employed always occur at the bottom of the list and when the index is not 
Table 6. Sensitivity Analysis Results for the Choice of Weights and Aggregation Function

\begin{tabular}{|c|c|c|c|c|c|c|c|c|c|c|c|c|}
\hline \multirow[b]{2}{*}{ Sublocation } & \multicolumn{2}{|c|}{$\mathrm{WPI}_{1, \mathrm{NW}, A}$} & \multicolumn{2}{|c|}{$\mathrm{WPI}_{2, W, A}$} & \multicolumn{2}{|c|}{$\mathrm{WPI}_{3, W, A}$} & \multicolumn{2}{|c|}{$\mathrm{WPI}_{1, \mathrm{NW}, G}$} & \multicolumn{2}{|c|}{$\mathrm{WPI}_{2, W, G}$} & \multicolumn{2}{|c|}{$\mathrm{WPI}_{3, W, G}$} \\
\hline & Score & Rank & Score & Rank & Score & Rank & Score & Rank & Score & Rank & Score & Rank \\
\hline Kapedo & 0.807 & 1 & 0.756 & 2 & 0.697 & 4 & 0.803 & 1 & 0.728 & 2 & 0.683 & 5 \\
\hline Lokori & 0.753 & 2 & 0.690 & 10 & 0.721 & 2 & 0.734 & 2 & 0.676 & 10 & 0.714 & 1 \\
\hline Lodwar Town & 0.721 & 3 & 0.635 & 27 & 0.699 & 3 & 0.692 & 5 & 0.517 & 59 & 0.656 & 10 \\
\hline Lokichar & 0.719 & 4 & 0.693 & 9 & 0.697 & 5 & 0.714 & 3 & 0.686 & 9 & 0.697 & 3 \\
\hline Kalomae & 0.710 & 5 & 0.803 & 1 & 0.723 & 1 & 0.697 & 4 & 0.774 & 1 & 0.697 & 2 \\
\hline Lotubae & 0.703 & 6 & 0.649 & 19 & 0.689 & 8 & 0.655 & 13 & 0.570 & 41 & 0.649 & 14 \\
\hline Lopiding & 0.700 & 7 & 0.704 & 6 & 0.694 & 6 & 0.690 & 6 & 0.706 & 5 & 0.692 & 4 \\
\hline Nakwamekwi & 0.698 & 8 & 0.715 & 4 & 0.692 & 7 & 0.678 & 8 & 0.713 & 4 & 0.674 & 6 \\
\hline Lorugum & 0.685 & 9 & 0.639 & 25 & 0.653 & 15 & 0.680 & 7 & 0.634 & 18 & 0.654 & 12 \\
\hline Tiya & 0.681 & 10 & 0.707 & 5 & 0.678 & 9 & 0.668 & 11 & 0.701 & 6 & 0.657 & 9 \\
\hline Kapua & 0.529 & 61 & 0.548 & 61 & 0.544 & 57 & 0.476 & 64 & 0.509 & 62 & 0.481 & 65 \\
\hline Nachokui & 0.528 & 62 & 0.527 & 69 & 0.513 & 69 & 0.495 & 58 & 0.492 & 72 & 0.482 & 63 \\
\hline Kanamkonyi & 0.522 & 63 & 0.633 & 28 & 0.526 & 62 & 0.464 & 67 & 0.561 & 45 & 0.471 & 71 \\
\hline Nakurio & 0.513 & 64 & 0.554 & 58 & 0.519 & 64 & 0.451 & 75 & 0.474 & 80 & 0.437 & 87 \\
\hline Kalapata & 0.511 & 65 & 0.534 & 64 & 0.497 & 81 & 0.494 & 59 & 0.534 & 52 & 0.486 & 61 \\
\hline Katilia & 0.511 & 66 & 0.512 & 80 & 0.498 & 79 & 0.484 & 60 & 0.505 & 64 & 0.483 & 62 \\
\hline Lomekui & 0.506 & 67 & 0.649 & 20 & 0.527 & 61 & 0.454 & 71 & 0.580 & 34 & 0.475 & 69 \\
\hline Atalakamusio & 0.505 & 68 & 0.481 & 93 & 0.484 & 86 & 0.442 & 80 & 0.450 & 88 & 0.437 & 86 \\
\hline Kalemungorok & 0.504 & 69 & 0.530 & 68 & 0.507 & 72 & 0.483 & 62 & 0.499 & 67 & 0.488 & 60 \\
\hline Lokiriama & 0.503 & 70 & 0.500 & 88 & 0.487 & 85 & 0.450 & 76 & 0.474 & 79 & 0.444 & 81 \\
\hline Kakimat & 0.396 & 108 & 0.442 & 106 & 0.418 & 108 & 0.362 & 106 & 0.428 & 97 & 0.381 & 106 \\
\hline Lokipoto & 0.390 & 109 & 0.388 & 112 & 0.391 & 109 & 0.339 & 110 & 0.352 & 112 & 0.343 & 111 \\
\hline Kanaodon & 0.388 & 110 & 0.391 & 111 & 0.387 & 111 & 0.380 & 101 & 0.369 & 108 & 0.380 & 107 \\
\hline Loruth/Esokon & 0.385 & 111 & 0.347 & 115 & 0.353 & 115 & 0.364 & 104 & 0.333 & 113 & 0.345 & 110 \\
\hline Kochodin & 0.384 & 112 & 0.421 & 110 & 0.389 & 110 & 0.375 & 103 & 0.369 & 109 & 0.384 & 105 \\
\hline Loremeit & 0.382 & 113 & 0.333 & 117 & 0.354 & 114 & 0.306 & 113 & 0.000 & 116 & 0.297 & 115 \\
\hline Nakalalei & 0.378 & 114 & 0.441 & 107 & 0.373 & 112 & 0.344 & 108 & 0.386 & 106 & 0.348 & 109 \\
\hline Loito & 0.358 & 115 & 0.336 & 116 & 0.357 & 113 & 0.306 & 114 & 0.298 & 114 & 0.309 & 114 \\
\hline Kobwin & 0.357 & 116 & 0.376 & 113 & 0.327 & 117 & 0.000 & 117 & 0.000 & 117 & 0.000 & 117 \\
\hline Nanam & 0.325 & 117 & 0.369 & 114 & 0.337 & 116 & 0.304 & 115 & 0.357 & 110 & 0.319 & 113 \\
\hline Average & 0.535 & & 0.557 & & 0.537 & & 0.492 & & 0.515 & & 0.496 & \\
\hline
\end{tabular}

Note: In bold are sublocations included in the second sensitivity analysis.

penalized by any variable. At the very bottom of the list we mainly find the same sublocations, though as mentioned above, scores are much lower if a geometric function is used. As might be expected, the biggest changes in rank (lost of more than 10 positions because of the aggregated function) are for locations which score less than 0.2 at least in one variable. Concluding, we highlight the fact that rankings are not always robust and thus aggregation methods are exposed to certain extent to different uncertainty sources. The structuring process, and in this case above all, the method used for the selection of indicators clearly determine the ranking.

For performing second sensitivity analysis, three sublocations were selected based on their rank position (top, medium, and low position). The indicator value of water quantity and "humanhuman conflicts" was varied from 0 to 1 in the original data set, and the WPI values using above six aggregation functions were computed. Table 7 shows the percentage variation of the WPI values over the minimum value for the indicator variation $(X i$ $=0)$ for all the three sublocations. The coefficients of determination $\left(R^{2}\right)$ of respective linear regressions are also presented to illustrate the linear behavior of all aggregations with variations in the indicator value.

As in first analysis, it can be observed in Table 7 that functions
$\mathrm{W}_{2, W, A}$ and $\mathrm{W}_{2, W, G}$ exhibit the highest sensitivity in comparison to other aggregation functions, though all methods are to some extent sensitive to the indicator variation. At the top positions (Kalomae), no significant changes occur. However, positions at the medium (Nachokui) and bottom (Loito) of the rank appear to be more sensitive. We see a different pattern depending on the indicator, and this is due to the lower values of the use subindex (regardless the alternative for selection of indicators), while the resources component exhibits the highest scores. For example, for the "water conflicts" variable (included in the use component), geometric functions show biggest changes with respect to indicator variations. Furthermore, all six functions selected for the sensitivity analysis show a uniform and linear behavior $\left(R^{2} \approx 1\right)$ with changes in the variable value for both selected indicators (Table 7).

\section{Results and Discussion}

The aim of previous analysis was to test the applicability and validity of different methodologies to estimate the degree of water poverty at local scale. To exemplify the utilization of the WPI, an 

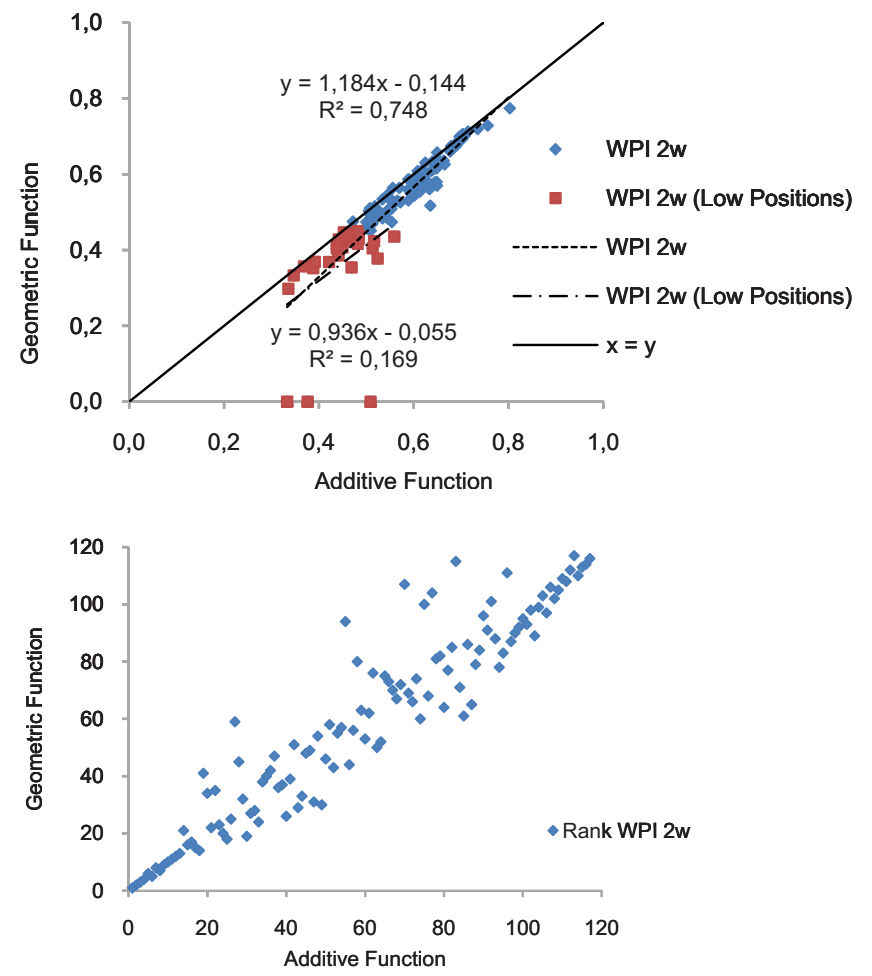

Fig. 2. Geometric function versus additive function: (a) $\mathrm{WPI}_{2, W, G}$; (b) rank of $\mathrm{WPI}_{2, W, G}$

initial case study has been developed for the Turkana District. The most appropriate aggregation function is to be selected on the basis of the aforementioned criteria. In this respect, the results show that no proposed method produce ambiguous results, in which final index would indicate areas suffering from high levels of water scarcity as nonwater poor locations.

In contrast, all aggregation functions suffer to a certain extent from the eclipsity problem. It is gleaned from the results nonetheless that linear aggregation functions are more eclipsed in comparison to multiplicative function. According to each ranking (for additive methods), 30 top positions include a not inconsiderable number of locations that suffer at least from one variable $(X i$ $<0,3)$; i.e., four $\left(\mathrm{WPI}_{1, \mathrm{NW}, A}\right)$; one $\left(\mathrm{WPI}_{2, W, A}\right)$; and two positions $\left(\mathrm{WPI}_{3, W, A}\right)$. If similar analysis is undertaken for the multiplicative functions, the eclipsity produced is smaller; i.e., one (WPI $\mathrm{WWW}_{1, \mathrm{NW}}$ ); $0\left(\mathrm{WPI}_{2, W, G}\right)$; and one position $\left(\mathrm{WPI}_{3, W, G}\right)$. It can also be seen that usage of less indicators (Alternative 2) shows far lower eclipsity as compared to two other alternatives, and this is acknowledged by Swamee and Tyagi (2000) who stated that "with the increase in the number of variables, the eclipsing problem progressively worsens." With regard to the weighting techniques, one has to note that introduction of multivariate analysis does not change the results spectacularly. On the basis of this criterion, the weighted geometric mean method $\mathrm{WPI}_{2, W, G}$ produces the least eclipsed results.

Similarly, it has been discussed earlier that an additive aggregation function should be applied only if indicators are mutually preferentially independent. It is unrealistic to assume that no synergies exist among the variables of the index. Furthermore, an undesirable feature of additive aggregations is the implied full compensability. As in the water poverty context different goals need to be considered simultaneously (all variables of the WPI are equally legitimate), noncompensatory aggregation procedures are recommended, and the use of a geometric function might be an in-between solution. Based on the sensitivity analysis of six aggregation methods, it is inferred that $\mathrm{WPI}_{2, W, G}$ exhibits the highest sensitivity and a linear behavior with variations in indicator values. In accordance with all specified criteria, it can thus be concluded that the weighted multiplicative function $\left(\mathrm{WPI}_{2, W, G}\right)$ is the most appropriate aggregation method for estimation of water poverty.

Finally, the index provides a starting point for analysis, which has to be deepened going back to the detail. The usefulness of the WPI not only lies in its final values, but also in its components themselves; which provide a rapid diagnosis for understanding the links between poverty, resource accessibility and institutional capacity. In this respect, a focus on the variables and indicators should allow analysts to identify the source of the problem in particular places and direct attention to those water sector needs that require special policy attention. For this purpose, the way the index and its components are disseminated is of primary importance, as this influence its interpretation.

In this study, main goal was a thorough discussion with regard to accuracy of index construction methodology, and it was not a deep analysis of water problems at a particular location. However, a map has been developed (Fig. 3) to show at a glance the level of water poverty based on the index values, which enables policy planners to quickly identify the locations in which to focus their efforts for maximum impact (Henninger 1998). Additionally, another paper (Giné, R., and Pérez-Foguet, A. "Application of a revised WPI to target the water poor." Water Sci. Technol., under review) assessed the water poverty situation at Turkana district through a comprehensive analysis of the WPI results.

Table 7. Sensitivity Analysis Results for Change in Two Variables Value

\begin{tabular}{|c|c|c|c|c|c|c|c|c|c|c|c|c|}
\hline \multirow[b]{3}{*}{$\begin{array}{l}\text { Aggregation } \\
\text { function }\end{array}$} & \multicolumn{6}{|c|}{ Water quantity } & \multicolumn{6}{|c|}{$\mathrm{H}-\mathrm{H}$ water conflicts } \\
\hline & \multicolumn{2}{|c|}{ Kalomae } & \multicolumn{2}{|c|}{ Nachokui } & \multicolumn{2}{|c|}{ Loito } & \multicolumn{2}{|c|}{ Kalomae } & \multicolumn{2}{|c|}{ Nachokui } & \multicolumn{2}{|c|}{ Loito } \\
\hline & $\begin{array}{c}\Delta \\
(\%)\end{array}$ & $R^{2}$ & $\begin{array}{c}\Delta \\
(\%)\end{array}$ & $R^{2}$ & $\begin{array}{c}\Delta \\
(\%)\end{array}$ & $R^{2}$ & $\begin{array}{c}\Delta \\
(\%)\end{array}$ & $R^{2}$ & $\underset{(\%)}{\Delta}$ & $R^{2}$ & $\underset{(\%)}{\Delta}$ & $R^{2}$ \\
\hline $\mathrm{WPI}_{1, \mathrm{NW}, A}$ & 10.36 & 1 & 13.54 & 1 & 19.61 & 1 & 5.97 & 1 & 8.15 & 1 & 11.59 & 1 \\
\hline $\mathrm{WPI}_{2, W, A}$ & 18.53 & 1 & 27.34 & 1 & 41.68 & 1 & 7.07 & 1 & 11.10 & 1 & 16.67 & 1 \\
\hline $\mathrm{WPI}_{3, W, A}$ & 17.18 & 1 & 23.28 & 1 & 32.32 & 1 & 4.62 & 1 & 6.61 & 1 & 9.22 & 1 \\
\hline $\mathrm{WPI}_{1, \mathrm{NW}, G}$ & 10.76 & 0.997 & 9.94 & 0.997 & 9.59 & 0.997 & 5.36 & 0.999 & 13.99 & 0.978 & 31.11 & 0.995 \\
\hline $\mathrm{WPI}_{2, W, G}$ & 16.55 & 0.994 & 17.70 & 0.993 & 19.04 & 0.994 & 6.47 & 0.998 & 27.08 & 0.838 & 111.68 & 0.977 \\
\hline $\mathrm{WPI}_{3, W, G}$ & 16.13 & 0.995 & 14.95 & 0.996 & 14.43 & 0.996 & 3.63 & 1 & 10.99 & 0.978 & 27.26 & 0.996 \\
\hline
\end{tabular}




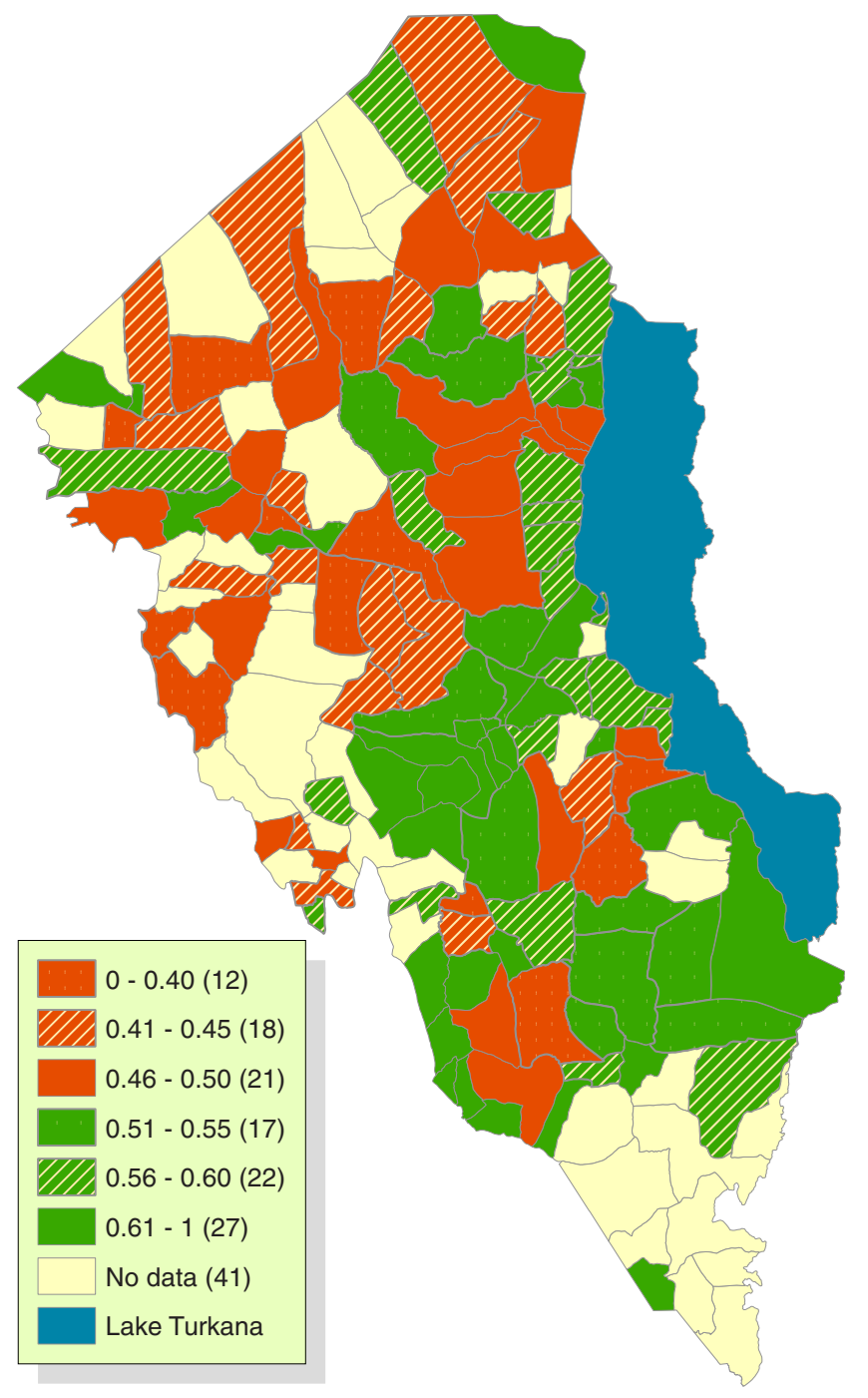

Fig. 3. WPI values, at sublocation level (in brackets are number of sublocations)

\section{Conclusions}

The WPI has proven to be an adequate tool for more effective water policy making. The revision presented here makes the index more theoretically sound and statistically founded. An improved method to develop the index is described, which may be summarized in the following steps: selection of indicators (from available information sources where possible) that would capture the essence of the five components of the index, principal component analysis, assignment of weights for each variable, aggregation of variables, and validation of the composite. This approach has been piloted in the Turkana District, using data provided by a comprehensive record of the water sources carried out by UNICEF. In practice, if the methodology is to be implemented at any other location, it would be recommended that the variables could be represented by existing but accurate data, thus providing a cost-effective solution to target the water poor.

Three different alternatives to select and combine indicators at subindex level have been proposed, two different weighting systems have been applied, and two aggregation forms have been used to construct the index. Six alternative methods are compared.
It has been found that the aggregation function $\mathrm{WPI}_{2, W, G}$ (selection of indicators based on PCA, and weighted geometric mean of subindices) presents less eclipsing problems. Furthermore, this function does not allow compensability among the different variables of the index. Based on the sensitivity analysis, it is inferred that it also exhibits the highest sensitivity and a linear behavior with variations in indicator values. Therefore, the weighted multiplicative function $\left(\mathrm{WPI}_{2, W, G}\right.$ ) is presented as the most suitable aggregation method for assessment of the WPI at local scale.

\section{Acknowledgments}

The writers would like to extend thanks to UNICEF (Kenya Regional Office) and to Rural Focus Ltd. Consultancy, who has contributed and provided support for the assessment in various ways. Further thanks go to two anonymous referees for useful comments and suggestions. Financial support from the Agència Catalana de Cooperació al Desenvolupament (Generalitat de Catalunya) and the Centre de Cooperació per al Desenvolupament (Universitat Politècnica de Catalunya) is gratefully acknowledged.

\section{References}

Booysen, F. (2002). "An overview and evaluation of composite indices of development." Soc. Indic. Res., 59, 115-151.

Cullis, J., and O'Regan, D. (2004). "Targeting the water-poor through water poverty mapping." Water Policy, 6, 397-411.

Esty, D. C., Levy, M. A., Srebotnjak, T., and de Sherbinin, A. (2005). 2005 environmental sustainability index: Benchmarking national environmental stewardship, Yale Center for Environmental Law and Policy, New Haven, CT.

Falkenmark, M. (1986). "Fresh water-Time for a modified approach." Ambio, 15(4), 192-200.

Feitelson, E., and Chenoweth, J. (2002). "Water poverty: Towards a meaningful indicator." Water Policy, 4, 263-281.

Giné, R., and Pérez-Foguet, A. (2009). "Enhancing sector data management to target the water poor." Proc., 34th WEDC Int. Conf., WEDC, Addis Adaba, Ethiopia.

Government of Kenya-UNICEF. (2006). "Water, schools and health management information system (MIS) for Turkana district." Final Rep., Nairobi, Kenya.

Hajkowicz, S. (2006). "Multi-attributed environmental index construction." Ecologic. Econ., 57, 122-139.

Hajkowicz, S., and Collins, K. (2007). "A review of multiple criteria analysis for water resource planning and management." Water Resour. Manage., 21, 1553-1566.

Heidecke, C. (2006). "Development and evaluation of a regional water poverty index for Benin.” EPT Discussion Paper No. 145, International Food Policy Research Institute, Washington, D.C.

Henninger, N. (1998). Mapping and geographic analysis of human welfare and poverty: Review and assessment, World Resources Institute, Washington, D.C.

Jiménez, A., Molinero, J., and Pérez-Foguet, A. (2008). "Monitoring water poverty: A vision from development practitioners." Proc., Water Ethics, 3rd Botín Foundation Water Workshop, Taylor and Francis, London.

Joint Monitoring Programme. (2000). "Global water supply and sanitation assessment report 2000." Joint Monitoring Programme for Water Supply and Sanitation, 〈http://www.wssinfo.org (June 2009).

Komnenic, V., Ahlers, R., and van der Zaag, P. (2009). "Assessing the usefulness of the Water Poverty Index by applying it to a special case: Can one be water poor with high levels of access?" Phys. Chem. Earth, Parts A/B/C, 34(4-5), 219-224. 
Kumar, D., and Alappat, B. J. (2004). "Selection of the appropriate aggregation function for calculating leachate pollution index." Pract. Period. Hazard. Toxic Radioact. Waste Manage., 8(4), 253-264.

Lawrence, P., Meigh, J., and Sullivan, C. (2003). "The Water Poverty Index: An international comparison." Keele economic research papers 2002/19, Keele University, Staffordshire, U.K.

Lohani, B. N., and Todino, G. (1984). "Water quality index for Chao Phraya River." J. Environ. Eng., 110(6), 1163-1176.

Molle, F., and Mollinga, P. (2003). "Water poverty indicators: Conceptual problems and policy issues." Water Policy, 5(5), 529-544.

Munda, G., and Nardo, M. (2005a). "Constructing consistent composite indicators: The issue of weights." Rep. No. EUR 21834 EN, European Commission, JRC, Ispra, Italy.

Munda, G., and Nardo, M. (2005b). "Non-compensatory composite indicators for ranking countries: A defensible setting." Rep. No. EUR 21833 EN, European Commission, JRC, Ispra, Italy.

Nardo, M., Saisana, M., Saltelli, A., Tarantola, S., Hoffman, A., and Giovannini, E. (2005). "Handbook on constructing composite indicators: Methodology and user guide." OECD statistics working paper, OECD, Statistics Directorate, Paris.

Organisation for Economic Cooperation and Development (OECD). (1993). "Core set of indicators for environmental performance reviews: A synthesis report by the Group on the State of the Environment." Rep. No. 83, Paris.

Podinovskii, V. V. (1994). "Criteria importance theory." Math. Soc. Sci., $27,237-252$
Saisana, M., and Tarantola, S. (2002). "State-of-the-art report on current methodologies and practices for composite indicator development." Rep. No. EUR 20408 EN, European Commission, JRC, Ispra, Italy.

Shah, T., and van Koppen, B. (2006). "Is India ripe for integrated resources management? Fitting water policy to national development context." Econ. Polit. Wkly., 41(31), 3413-3421.

Singh, R. P., Nath, S., Prasad, S. C., and Nema, A. K. (2008). "Selection of suitable aggregation function for estimation of aggregate pollution index for River Ganges in India." J. Environ. Eng., 126(5), 451-455.

Slottje, D. J. (1991). "Measuring the quality of life across countries." Rev. Econ. Stat., 73(4), 684-693.

Sullivan, C. (2002). "Calculating a Water Poverty Index." World Dev., 30(7), 1195-1210.

Sullivan, C., and Meigh, J. (2003). "Considering the Water Poverty Index in the context of poverty alleviation." Water Policy, 5, 513-528.

Sullivan, C. A., et al. (2003). "The Water Poverty Index: Development and application at the community scale." Nat. Resour. Forum, 27, 189-199.

Swamee, P. K., and Tyagi, A. (2000). "Describing water quality with aggregate index.” J. Environ. Eng., 134(8), 689-701.

Swamee, P. K., and Tyagi, A. (2007). "Improved method for aggregation of water quality subindices." J. Environ. Eng., 133(2), 220-225.

Thomson, M., Okuni, P. A., and Sansom, K. (2005). "Sector performance reporting in Uganda-From measurement to monitoring and management." Proc., 31st WEDC Int. Conf., WEDC, Kampala, Nigeria. 